\title{
O DESAFIO DA FORMAÇÃO DOCENTE NO MUNICÍPIO DE MANAUS DIANTE DA NOVA PROPOSTA CURRICULAR DE EDUCAÇÃO DE JOVENS E ADULTOS
}

\author{
A. P. F. ARAÚJO e G. N. OLIVEIRA \\ Instituto Federal de Educação, Ciência e Tecnologia do Amazonas - IFAM \\ and_paraujo@hotmail.com*
}

Artigo submetido em outubro/2014 e aceito em dezembro/2014

DOI: $10.15628 /$ rbept.2014.3472

\section{RESUMO}

O O presente trabalho teve como objetivo analisar o percurso formativo dos professores que atuam na modalidade de Educação Jovens e Adultos (EJA) da Secretaria Municipal de Educação (SEMED) a partir do ano de 2014. Seguindo as características da pesquisa exploratória foi utilizada a técnica de pesquisa bibliográfica e coleta de dados referentes ao ano letivo de 2014 e 2015, junto aos departamentos de estatística da SEMED para levantamento da oferta da EJA e sobre o processo de formação dos docentes no município. O projeto intitulado "Gestão do ensino noturno: desafios e perspectivas de aprendizagens" teve a perspectiva de capacitar 871 professores, cuja concepção teórica busca articular metodologias que privilegiam a troca de saberes e reflexões a partir da valorização das experiências de aprendizagens a serem construídas. Diante dos desafios da educação brasileira, o projeto de formação docente para atender verdadeiramente as perspectivas da EJA, deve ser pautado numa dimensão emancipadora do aluno levando em consideração os ritmos diferenciados de aprendizagem (na esfera individual e coletiva), as características pessoais e profissionais, bem como o desenvolvimento de métodos diversificados que permitam partir de problemáticas da realidade vivenciada por alunos e professores.

PALAVRAS-CHAVE: EJA, formação docente, concepção metodológica.

\section{TEACHER TRAINING CHALLENGE IN THE MUNICIPALITY OF MANAUS BEFORE THE NEW PROPOSAL OF CURRICULUM ADULT EDUCATION}

\begin{abstract}
This study aimed to analyze the training course for teachers who work in the form of Youth and Adult Education (EJA) of the Municipal Education (SEMED) from the year 2014. Following the exploratory characteristics we used the literature of technical and data collection for the school year 2014 to 2015 , from the SEMED statistical departments to survey the supply of adult education and the process of training teachers in the county. The project entitled "Management of night courses: challenges and perspectives of learning" had the prospect of train 871 teachers, whose theoretical framework seeks to
\end{abstract}

articulate methodologies that favor the exchange of knowledge and reflections from the appreciation of learning experiences to be built. Facing the challenges of the Brazilian education, teacher training project to truly meet the perspectives of adult education should be based on a emancipatory dimension of the student taking into consideration the different paces of learning (in individual and collective sphere), the personal and professional characteristics, and the development of diversified methods to problems from the reality experienced by students and teachers 


\section{BREVE CONTEXTUALIZAÇÃO DA EDUCAÇÃO DE JOVENS E ADULTOS NA EDUCAÇÃO BRASILEIRA}

Segundo o documento das Diretrizes Curriculares para a Educação de Jovens e Adultos, (2006, p.16) a educação de jovens e adultos vem passando por transformações emergenciais e conquistas recentes quanto aos processos de alfabetização, de modo que o reconhecimento e a definição desta modalidade como política pública de acesso e continuidade à escolarização básica.

No final do século XIX e início do século XX, num contexto de emergente desenvolvimento urbano industrial e sob forte influência da cultura europeia, foram aprovados projetos de leis que enfatizavam a obrigatoriedade da educação de adultos. Buscava-se aumentar o contingente eleitoral, sobretudo no primeiro período republicano para atender aos interesses das elites.

Com a Reforma João Alves, em 1925 surgiu o ensino noturno para jovens e adultos, com o objetivo de atender aos interesses da classe dominante que, por volta de 1930, iniciava um movimento contra o analfabetismo. Desta forma, a educação escolar passou a ser considerada baluarte do progresso e do desenvolvimento de uma nação $(2006$, p. 17).

No contexto brasileiro a Constituição Federal de 1934, instituíul a obrigatoriedade e a gratuidade do ensino primário para todos, contudo, era incipiente a sua oferta, a considerar os altos índices de analfabetismo no país. Segundo Fausto, 1999 o índice de analfabetismo caiu de $69,9 \%$, em 1920 , para $56,2 \%$, tomando por base a população de 15 anos ou mais em 1940 . Naquele mesmo ano, a educação de jovens e adultos era tema de política educacional.

A partir de 1985, com a Nova República, o governo federal rompeu com a política de EJA do período militar, extinguiu o Mobral e criou a Fundação Nacional para Educação de Jovens e Adultos (Fundação Educar). Essa Fundação apoiou técnica e financeiramente algumas iniciativas de educação básica de jovens e adultos, conduzidas por instâncias administrativas municipais e instituições da sociedade civil.

O Ministério da Educação em 1986, organizou uma Comissão para a elaboração de Diretrizes Curriculares Político-Pedagógicas da Fundação Educar, a qual reivindicou a oferta pública, gratuita e de qualidade do ensino de $1 .^{\circ}$ Grau aos jovens e adultos, dotando-o de identidade própria. A Comissão fazia ainda recomendações relativas à criação de uma política nacional de educação de jovens e adultos, ao seu financiamento e à revisão crítica da legislação nessa área.

A busca pela ampliação do atendimento à escolarização da população jovem e adulta pelos sistemas estaduais se vincula às conquistas legais referendadas pela Constituição Federal de 1988, na qual a EJA passou a ser reconhecida como modalidade específica da educação básica. A promulgação da Lei n. 9394/96, estabeleceu como uma modalidade nas etapas do EF e Médio, assumindo especificidade própria.

Com a redução da idade para 15 e 18 anos, nos níveis de conclusão da Educação Básica, a legislação fez aumentar significativamente a demanda por esta modalidade e, portanto, fez reduzir a demanda no ensino regular, espaço de formação mais adequado aos adolescentes e jovens com pequena defasagem série/idade. 


\subsection{Conceito e funções da EJA}

Segundo os Parâmetros Curriculares da Educação Básica (PCNs) 2001, o Brasil continua exibindo um número enorme de analfabetos. O Instituto Brasileiro de Geografia e Estatística (IBGE) no ano de 2013 a taxa de analfabetismo das pessoas acima de 15 anos no Brasil voltou a cair. De acordo com a Pesquisa Nacional por Amostra de Domicílios (PNAD), o país registrou cerca de 13 milhões de analfabetos nesta faixa etária no ano passado, o que corresponde a 8,3\% da população. O resultado é 0,4\%, um percentual abaixo do registrado em 2012 (8,7\%).

Apesar da queda anual e da redução dos números de pessoas que não sabem ler ou escrever por falta de condições de acesso ao processo de escolarização deve ser motivo de autocrítica constante e severa. Pois revela a fragilidade do sistema educacional vigente onde atualmente percebemos o encerramento das atividades das escolas que atendem o ensino noturno, correspondendo a modalidade da EJA.

Neste sentido, Magda Soares (1998, p 24) relata que "um adulto pode ser analfabeto, porque marginalizado social e economicamente, mas, se vive em um meio em que a leitura e a escrita têm presença forte, se interessa em ouvir a leitura de jornais feita por um alfabetizado". Desse modo, a função reparadora da EJA, evidencia os limites de uma educação que vem ao encontro dos direitos civis pela restauração de um direito negado - o direito a uma escola de qualidade - mas também o reconhecimento daquela igualdade ontológica de todo e qualquer ser humano.

Dessa negação, evidente na história brasileira, resulta uma perda: o acesso a um bem real, social e simbolicamente importante, percebe-se que esse acesso não assegura a permanência do aluno até o final do segmento por inúmeras situações. Contudo, não se deve confundir a noção de reparação com a de suprimento, como diz o Parecer CNE/CEB no 4/98: "Nada mais significativo e importante para a construção da cidadania que a compreensão de que a cultura não existiria sem a socialização das conquistas humanas".

O Parecer no 04/98 evidenciam que os processos educativos possibilitam ao indivíduo jovem ou adulto retomar seu potencial, desenvolver suas habilidades e competências adquiridas na educação extraescolar e na própria vida.

Desse modo, percebe-se que a história da educação de jovens e adultos no Brasil vem demonstrando alguns desafios a serem ainda superados no atual contexto das políticas públicas, principalmente no que se refere ao processo de qualificação da oferta de matrícula na modalidade de educação de jovens e ações culturais e científicas voltadas ao amplo reconhecimento desta etapa de educação formal, como estratégias de promoção de equidade educativa e social.

\subsection{Educação de Jovens e Adultos hoje}

Segundo as Diretrizes Curriculares da Educação Básica, a Constituição de 1980 dará um passo significativo em direção a uma nova concepção de Educação de Jovens e Adultos. Desta forma, o Ensino Fundamental extensivo aos adultos ganha notoriedade com o segmento da EJA, pois revela notável ampliação dos direitos subjetivos para os adultos já posta na Constituição de 1934. A LDB acompanha essa orientação, suprimindo a expressão Ensino Supletivo, embora mantendo o termo supletivo para os exames. Contudo, ainda se mantem a continuidade no interior dessa nova concepção. 
Do ponto de vista conceitual, além da extensão da escolaridade obrigatória formalizada em 1967, os artigos 37 e 38 da LDB em vigor dão à EJA uma dignidade própria, mais ampla, e eliminam uma visão equivocada com relação ao assinalado como regular. O art. 4으, inciso VII, da LDB é claro quando cita o dever do Estado com educação escolar pública será efetivado mediante a garantia de "oferta de educação regular para jovens e adultos, com características e modalidades adequadas às suas necessidades e disponibilidades, garantindo-se aos que forem trabalhadores as condições de acesso e permanência na escola".

Desde que a EJA passou a fazer parte constitutiva da Lei 9394/96, tornou-se modalidade da Educação Básica sendo reconhecida como direito público subjetivo na etapa do EF. Deste modo, a modalidade na atualidade tem função reparadora, pois ao assinalar tanto os cursos quanto os exames supletivos tem na sua proposta o encurtamento da escolarização básica, compreendidos dentro dos novos referenciais legais e da concepção da EJA.

A Resolução no 3, de 15 de junho de 2010 em seu Art. 1ㅇinstitui Diretrizes Operacionais para a EJA nos aspectos relativos à duração dos cursos e idade mínima para ingresso nos cursos e a certificação nos exames de EJA, sendo desenvolvida por meio da Educação a Distância (EAD), observadas pelos sistemas de ensino, na oferta e na estrutura dos cursos e exames de EF e Ensino Médio que se desenvolvem em instituições próprias integrantes dos Sistemas de Ensino Federal, Estaduais, Municipais e do Distrito Federal.

Em seu parágrafo único, institui a oferta variada para o pleno atendimento dos adolescentes, jovens e adultos situados na faixa de 15 (quinze) anos ou mais, com defasagem idade-série, tanto sequencialmente no ensino regular quanto na EJA, assim como nos cursos destinados à formação profissional, nos termos do § 30 do artigo 37 da Lei no 9.394/96, tornandose necessário:

I - fazer a chamada ampliada de estudantes para o Ensino Fundamental em todas as modalidades, tal como se faz a chamada das pessoas de faixa etária obrigatória do ensino;

II - incentivar e apoiar as redes e sistemas de ensino a estabelecerem, de forma colaborativa, política própria para o atendimento dos estudantes adolescentes de 15 (quinze) a 17 (dezessete) anos, garantindo a utilização de mecanismos específicos para esse tipo de alunado que considerem suas potencialidades, necessidades, expectativas em relação à vida, às culturas juvenis e ao mundo do trabalho, tal como prevê o artigo 37 da Lei no 9.394/96, inclusive com programas de aceleração da aprendizagem, quando necessário;

Ainda sobre a Resolução no 3, de 15 de junho de 2010 em seu Art. 4ㅇq quando se reporta à duração dos cursos presenciais de EJA, mantém-se a formulação do Parecer CNE/CEB no 29/2006, acrescentando o total de horas a serem cumpridas, independentemente da forma de organização curricular:

I - para os anos iniciais do Ensino Fundamental, a duração deve ficar a critério dos sistemas de ensino;

II - para os anos finais do Ensino Fundamental, a duração mínima deve ser de 1.600 (mil e seiscentas) horas; 
III - para o Ensino Médio, a duração mínima deve ser de 1.200 (mil e duzentas) horas.

No conjunto desses instrumentos legais sobre a regulamentação da EJA, um avanço importante foi a inclusão da EJA no Fundo de Manutenção e Desenvolvimento da Educação Básica e de Valorização dos Profissionais da Educação (FUNDEB), um passo importante considerando a partir de então a ampliação e o financiamento para abertura de novas turmas de educação de jovens e adultos, com foco nas populações do campo, quilombolas, indígenas, egressos do Brasil Alfabetizado e pessoas em privação de liberdade. ${ }^{1}$

\section{OS DESAFIOS DE UMA ATUAÇÃO DOCENTE NA EJA}

A EJA atualmente passa por uma revisão, devido sua importância e autenticidade na educação básica, na direção de superar a visão de modalidade assistencial, de ajuda aos menos favorecidos e de caráter compensatória. No universo da EJA os educadores e demais atores envolvidos são membros importantes que, no exercício de sua função docente, desempenham um papel de mediação entre o sujeito que conhece e o objeto do conhecimento, consolidando, assim, a função social da escola.

Nesse sentido, a prática docente nesta modalidade pretende superar a visão técnica de mera aprendizagem de conteúdos, desarticulada e sem continuidade, rigidamente delimitada e que desconsidera a vivência dos educandos e oferecer, em contrapartida, o ensino com aprendizagens significativas, conectadas às necessidades, interesses e aos contextos existentes.

É importante que o docente que atua na EJA desenvolva práticas que tenham como ponto de partida o estabelecimento da relação teórico-prática na construção de saberes em sala de aula. Sendo importante, um processo de formação continuada que atenda à diversidade e as especificidades da EJA e acompanhem a dinamicidade que constitui o exercício da docência considerando o contexto escolar e as expectativas dos sujeitos escolares.

Sobre a importância da formação docente Freire (1996, p.92) destaca que:

[...] o professor que não leve a sério sua formação, que não estude que não se esforce para estar à altura de sua tarefa não tem força moral para coordenar as atividades de sua classe. Isto não significa, porém, que a opção e a prática democrática do professor ou da professora sejam determinadas pela sua competência cientifica. Há professores e professoras cientificamente preparados, mas autoritários a toda prova. O que quero dizer é que a incompetência profissional desqualifica a autoridade do professor.

A formação docente é sobremaneira um ponto crucial na consolidação da educação de qualidade nos diversos níveis e modalidades uma vez que grande parte dos professores são produtos de uma formação inicial cujas habilidades metodológicas e científicas, seguiram uma base abstrata e conteudistas, não havendo espaço para inovação ou criação em seu processo de aprendizagem, bem como no decorrer do exercício da prática de ensino.

\footnotetext{
${ }^{1}$ Disponível em: http://goo.gl/LPt9Ah
} 
O modelo convencional de formação docente a rigor, habilmente, prepara o professor para transmitir informações através de aulas instrucionistas e focados na memorização do conteúdo escolar, o que não atende aos princípios da educação científica, que implica na atitude do professor em organizar estratégias para se envolver profundamente na aprendizagem do aluno. $O$ exercício da docência engloba, conforme mencionam Kuiper e $\operatorname{Volman}^{2}$ (2008, p.13) a habilidade do professor de fazer das tecnologias um meio de aprendizagem, não fim em si mesmas. Nesse sentido, Demo (2008, p. 13) ressalta que entre tantos desafios "está o de educar o estudante para pesquisar e elaborar na internet, não plagiar".

Dentre as habilidades a serem desenvolvidas pelo professor, torna-se importante o domínio as tecnologias da informação e comuicação (TICS) para que no exercício docente estabeleça conexões criativas com os recursos que poderão auxiliar os alunos da EJA a aprender e construir conhecimentos a partir de novas possibilidades que se sobrepõem ao livro didático, conhecendo as funcionalidades pedagógicas das ferramentas digitais, as plataformas de busca e de redes sociais.

Evidenciar o uso dos recursos tecnológicos para mobilizar maior interação e aprendizagem nos alunos, compreende um trabalho árduo de estruturação e contextualização da cultura perante a influência dos ambientes sociais levados para o interior da escola, integrando diferentes aspectos, como culturais, políticos, econômicos e sociais.

Desafiando desse modo, a escola como espaço formativo, a desenvolver uma prática integrada às demandas e mazelas da sociedade moderna, onde o tratamento didático do conteúdo escolar, principalmente na EJA, supere a visão fragmentada e distanciada da realidade, havendo nessa trajetória, o fortalecimento dos fundamentos científicos da formação cidadã do aluno para sua efetiva participação ativa na sociedade.

\section{METODOLOGIA}

Constitui-se numa pesquisa exploratória que se encontra na fase preliminar e conforme mencionam Prodanov e Freitas (2013, p. 51) "tem como finalidade proporcionar mais informações sobre o assunto que vamos investigar, possibilitando sua definição e seu delineamento". Seguindo o aporte da abordagem qualitativa definida por Triviños (2008) como aquela que se preocupa em conhecer uma realidade, captar seus significados e compreendê-los. A técnica de coleta de dados utilizada foi a pesquisa bibliográfica "que contribui para o embasamento teórico sobre os estudos já estruturados sobre o tema em questão" (PRODANOV e FREITAS, 2013, p. 55), além de coleta de dados referentes ao ano letivo de 2014 e 2015, junto ao Departamento de Planejamento - DEPLAN e a Divisão de Informação e Estatística - DIE termos acesso aos dados gerais das escolas que atendem a modalidade de Educação de Jovens e Adultos na Secretaria Municipal de Manaus.

\section{A FORMAÇÃO DOCENTE NA PERSPECTIVA DA EDUCAÇÃO DE JOVENS E ADULTOS NO MUNICÍPIO DE MANAUS.}

Mudanças significativas foram implementadas na oferta do Ensino Fundamental (EF) regular no turno noturno da Secretaria Municipal de Educação de Manaus (SEMED), com um

\footnotetext{
${ }^{2}$ (apud DEMO, 2008, p. 13)
} 
conjunto de dispositivos legais a aprovados pelo Conselho Municipal de Educação (CME), sendo a de $\mathrm{n}$ 0 04, de 22/04/2010 que trata da aprovação da Proposta Pedagógica da Educação de Jovens e Adultos - 10 Segmento, para as Escolas da Rede Municipal de Ensino e a Resolução no 07, de 15/09/2011, que estabelece normas para operacionalização da Educação de Jovens e Adultos (EJA) na Rede Municipal de Ensino de Manaus.

A partir deste cenário, o EF passa a ser oferecido apenas na modalidade EJA no turno noturno, organizado em 1 은 Segmento (anos iniciais) e 20 Segmento (anos finais). Sendo que o 10 Segmento tem a duração de 03 anos, sendo dividido em três fases: 1a fase (1ํano); 2a fase (2으 e 3ㅇ ano) e 3a fase (4ำ e 5ㅇ), cada fase é composta por 4 módulos. E o 2 ㅇ Segmento tem duração de 2 anos, dividido em 4a e 5 $\underline{a}$ fase. Cada fase é composta por 3 trimestres.

Com base nessa reorganização, foi necessário realizar a capacitação dos docentes para atuar nesta nova modalidade de ensino, nesta direção a Divisão de Desenvolvimento Profissional do Magistério (DDPM), elaborou uma proposta de formação intitulada "Gestão do ensino noturno: desafios e perspectivas de aprendizagens". O objetivo da capacitação é contribuir qualitativa e quantitativamente nos processos pedagógicos do ensino noturno, realizada ao longo do ano de 2014, cuja estruturação seguir o formato de módulos e cronograma específico.

No processo de formação docente, buscou-se focar nas opções metodológicas que se aplicam à EJA, orientadas por uma visão de mundo e de educação que articulam os contextos em que seus sujeitos estão inseridos; valorizando as experiências de aprendizagens vividas pelos alunos, a forma em que alunos jovens e adultos aprendem e os traços particulares das disciplinas a serem ensinadas e aprendidas, privilegiando a troca de saberes e reflexões (MANAUS, 2010, p. $31)$.

A formação docente na perspectiva atual do desenvolvimento profissional segundo Lima (2002, p. 2) "deve situar-se numa tendência dialético-reflexivo-crítica, organizada com base no contexto educativo, nas necessidades dos sujeitos imediatos da ação educacional formativa". 0 que implica considerar primeiramente a formação humana como um processo amplo que envolve aspectos da trajetória de vida-pessoal e profissional, que se caracteriza pela busca contínua de níveis elevados de saberes (saber, saber fazer e saber ser).

Nesse sentido, com as novas mudanças na estrutura curricular da EJA na rede de ensino do município de Manaus, a capacitação dos professores teve como foco a compreensão e as reais implicações da nova proposta, principalmente no que se refere a concepção metodológica e avaliação, bem como a nova configuração da atuação docente. Ao longo do processo de formação a SEMED pretende capacitar o total de 871 professores do ensino noturno, de 73 escolas municipais de todas as zonas geográficas, com o benefício estimado para mais de 15 mil alunos da modalidade. ${ }^{3}$

Ainda sobre a formação docente dos professores da SEMED, o projeto de formação "Gestão do ensino noturno: desafios e perspectivas de aprendizagens" busca apresentar aos professores um arcabouço de práticas renovadas para serem trabalhadas em sala de aula uma vez que parte da construção de possibilidades, considerando o perfil do alunado a ser atendido na EJA noite, visando combater o abandono escolar e melhorar a qualidade dos processos de ensino e aprendizagem.

\footnotetext{
${ }^{3}$ Disponível em: http://goo.gl/GQ2pX5
} 
Considerando que a referida rede possui uma oferta significativa de matrícula na EJA, mesmo sendo mais expressiva a demanda de matrícula para o EF nos turnos diurnos, os motivos da baixa procura podem estar relacionados à falta de segurança (principalmente em áreas onde domina o tráfico de drogas), a própria adesão dos alunos ao uso de entorpecentes, ingresso no mercado de trabalho ou até mesmo a aprovação antecipada no Exame Nacional do Ensino Médio (ENEM) ${ }^{4}$

Atualmente a referida Secretaria é composta por 501 unidades que atendem os anos iniciais e finais do Ensino Fundamental, além da Educação Infantil, sendo estas organizadas de acordo com as suas respectivas localizações nas zonas urbana e rural do município. As escolas são concentradas em Divisões Distritais Zonais/DDZs que atendem à necessidade de descentralizar as atividades pedagógicas e administrativas da rede municipal de ensino, regulamentada pela Lei no 590, de 13 de março de 2001. De acordo com os dados do Departamento de Informação e Estatística (DIE/SEMED) no ano de 2014, o quantitativo de 94 escolas municipais atenderem ao Programa de Educação de Jovens e Adultos (EJA), conforme demonstrado no Quadro 1.

Quadro 1- Total de alunos matriculados na EJA no ano letivo de 2014.

\begin{tabular}{|c|c|c|c|c|c|c|}
\hline \multirow[b]{2}{*}{ № } & \multirow{2}{*}{$\begin{array}{c}\text { DIVISÕES } \\
\text { REGIONAIS } \\
\text { EDUCACIONAIS }\end{array}$} & \multirow[b]{2}{*}{$\begin{array}{c}\text { ZONA } \\
\text { URBANA }\end{array}$} & \multirow[b]{2}{*}{$\begin{array}{c}\text { UNIDADES } \\
\text { EDUCACIONAIS }\end{array}$} & \multicolumn{3}{|c|}{ ALUNOS MATRICULADO NA EJA } \\
\hline & & & & $\begin{array}{c}1^{\circ} \\
\text { SEGMENTO }\end{array}$ & $\begin{array}{c}2^{\circ} \\
\text { SEGMENTO }\end{array}$ & TOTAL \\
\hline 1 & DRE I & Sul & 9 & 549 & 818 & 1.367 \\
\hline 2 & DRE ॥ & $\begin{array}{c}\text { Oeste/Centro } \\
\text { Oeste }\end{array}$ & 13 & 652 & 1.012 & 1.664 \\
\hline 3 & DRE III & Norte & 8 & 509 & 968 & 1.477 \\
\hline 4 & DRE IV & Centro-sul & 11 & 407 & 872 & 1.279 \\
\hline 5 & DRE V & Leste I & 15 & 1.263 & 1.461 & 2.724 \\
\hline 6 & DRE VI & Leste II & 14 & 857 & 1.612 & 2.469 \\
\hline 7 & DRE VII & Rural & 24 & 396 & 304 & 700 \\
\hline \multicolumn{3}{|c|}{ REDE MUNICIPAL } & 94 & 4.633 & 7.047 & 11.680 \\
\hline
\end{tabular}

Conforme dados do quadro, a DRE VII corresponde à zona rural do município de Manaus, concentrando o maior número de escolas, mas que não atendem ao maior quantitativo de alunos uma vez que sendo escolas da zona rural, circunstancialmente as comunidades se encontram mais dispersas e afastadas das sedes comunitárias, onde geralmente estão localizadas a estrutura física das escolas municipais.

A EJA tem sido uma modalidade de formação na educação básica que tem atendido um demanda significativa de matrícula no cenário nacional mesmo havendo o gargalo de altas taxas de abandono, e pode estar relacionado ao dado apontado pela Pesquisa Nacional por Amostra de Domicílios 2012 (PNAD), divulgada pelo Instituto Brasileiro de Geografia e Estatística (IBGE) mostrou que, dentre a população com 25 anos ou mais, o percentual de pessoas sem instrução

\footnotetext{
${ }^{4}$ Disponível em: http://goo.gl/2nF3Sd
} 
diminuiu de 15,1\% para 11,9\% entre 2011 e 2012. Já a proporção dos brasileiros que possuíam nível fundamental incompleto aumentou de $31,5 \%$ para $33,5 \%$ no mesmo período. $^{5}$

No contexto do município de Manaus, houve alteração na oferta da EJA para o ano letivo de 2015, com a redução do número de escolas por Divisão Distrital, onde somente 79 unidades educacionais iniciaram o ano letivo funcionando com turmas da EJA no turno noturno, conforme destacado no Quadro 2.

Quadro 2- Total de alunos matriculados na EJA no ano letivo de 2015.

\begin{tabular}{|c|c|c|c|c|c|c|c|}
\hline № & $\begin{array}{c}\text { DIVISÕES } \\
\text { REGIONAIS } \\
\text { EDUCACIONAIS }\end{array}$ & $\begin{array}{c}\text { ZONA } \\
\text { URBANA }\end{array}$ & $\begin{array}{c}\text { UNIDADES } \\
\text { EDUCACIONAIS }\end{array}$ & \multicolumn{2}{|c|}{ ALUNOS MATRICULADO NA EJA } \\
\hline 1 & DRE I & Sul & 9 & 541 & 1.391 & 1.932 \\
\hline 1 & SEGMENTO & SEGMENTO & TOTAL \\
\hline 3 & DRE II & $\begin{array}{c}\text { Oeste/Centro } \\
\text { Oeste }\end{array}$ & 11 & 721 & 1.385 & 2.106 \\
\hline 4 & DRE III & Norte & 8 & 489 & 1.454 & 1.943 \\
\hline 5 & DRE IV & Centro-sul & 9 & 602 & 1.259 & 1.961 \\
\hline 6 & DRE V & Leste I & 12 & 1.272 & 2.660 & 3.932 \\
\hline 7 & DRE VI & Leste II & 13 & 1.005 & 2.730 & 3.735 \\
\hline & REE VII & Rural & 14 & 286 & 331 & 617 \\
\hline
\end{tabular}

Fonte: SEMED/DIE/SIGEAM-2015.

Porém, conforme dados apontados no Quadro 2, é possível destacar que a redução no números de escolas não reprimiu a oferta de matrícula na EJA no município de Manaus. Observando o total de alunos matriculados no início de 2015, as escolas das respectivas Divisões: DRE III, DRE IV, DRE V e DRE VI aumentaram significativamente a matrícula no referido período em relação ao ano de 2014, principalmente no 2ㅇ Segmento. Já a DRE VII, houve a redução no quantitativo de escolas, porém o número de alunos matriculados se manteve.

Diante dos dados relacionados à matrícula dos alunos na EJA, é importante situar a formação docente para que garanta uma formação de qualidade dos alunos que buscam nessa modalidade, a oportunidade de concluir a formação básica e assim, integrar-se ao mercado de trabalho.

\section{ALGUMAS CONSIDERAÇÕES}

A história da educação de jovens e adultos no Brasil vem demonstrando alguns desafios a serem ainda superados no atual contexto das políticas públicas, no que se refere ao processo de ampliação da oferta de matrícula na modalidade de educação de jovens e, principalmente, na qualificação docente para atuar de moco crítico e criativo nesta etapa de educação formal.

$\mathrm{Na}$ tentativa de atender as mudanças da estrutura curricular da EJA na rede de ensino do município de Manaus, os professores têm sido inseridos no projeto de capacitação com foco na compreensão da concepção metodológica e avaliação, cujo enfoque converge para o

\footnotetext{
${ }^{5}$ Disponível em: http://goo.gl/LPt9Ah
} 
conhecimento de necessidades cognitivas e realidades sociais dos educandos visando uma formação científica, tecnológica, social e política dos alunos que buscam a EJA para dar prosseguimento no seu processo de formação.

Para isso, o projeto de formação "Gestão do ensino noturno: desafios e perspectivas de aprendizagens" busca apresentar aos professores um arcabouço de práticas renovadas a serem aplicadas na EJA, sendo orientado por uma visão de mundo de educação que articula os contextos em que seus sujeitos estão inseridos, a forma em que alunos jovens e adultos aprendem e os traços particulares das disciplinas curriculares, privilegiando a troca de saberes e reflexões a partir da valorização das experiências de aprendizagens a serem construídas.

Nesse sentido, a formação docente é uma política importante para assegurar melhores índices da modalidade de educação de jovens e adultos no contexto do município de Manaus, cuja oferta de matrícula atende a uma demanda reprimida da referida rede escolar, onde no ano letivo de 2015, houve a redução do número de escolas, funcionando apenas 79 no turno noturno.

Contudo, o projeto de formação docente para atender verdadeiramente as perspectivas da EJA, deve ser pautado numa perspectiva emancipadora do aluno que leve em consideração os ritmos diferenciados de aprendizagem (na esfera individual e coletiva), as características pessoais e profissionais, bem como o desenvolvimento de métodos diversificados que permitam partir de problemáticas da realidade vivenciada por alunos e professores.

\section{REFERÊNCIAS}

1. BRASIL. Lei n. 9394 de 20 dezembro de 1996. Estabelece as Diretrizes e Bases da Educação Nacional. Diário Oficial da União, Brasília, p. 027833, col. 1, 23 dez. 1996.

2. Parecer CNE/CEB № 11, de 10/05/2002. Diretrizes Curriculares Nacionais para a Educação de Jovens e Adultos.

3. Resolução CNE/CEB № 01, de 05/07/2000. Diretrizes Curriculares Nacionais Gerais para a Educação Básica.

4. Resolução CNE/CEB № 03, de 15/06/2010. Diretrizes Operacionais para a Educação de Jovens e Adultos nos aspectos relativos à duração dos cursos e idade mínima para ingresso nos cursos de EJA.

5. Resolução CNE/CEB № 04, de 15/06/2010. Diretrizes Curriculares Nacionais Gerais para a Educação Básica.

6. Ministério da Educação. Diretrizes nacionais para a educação de jovens e adultos. Brasília. 2000.

7. . Ministério da Educação. Proposta curricular para a educação de jovens e adultos. Volume 1. Brasília, 2002.

8. DEMO, Pedro. Habilidades do Século XXI. B. Téc. Senac: a R. Educ. Prof., Rio de Janeiro, v. 34, n.2, maio/ago. 2008. Disponível em: http://goo.gl/xfXs0. Acesso em 16 de outubro de 2015.

9. FAUSTO, Bóris. História do Brasil. 6.ed. São Paulo : Fundação para o Desenvolvimento da Educação, 1999.

10. FREIRE, Paulo. Pedagogia da Autonomia: Saberes necessários à prática educativa. São Paulo: 
30 ed. Paz e Terra, 2004.

11. LIMA, Maria da Glória Soares Barbosa. Discutindo a formação e o desenvolvimento profissional docente: a trajetória de uma pesquisa. Disponível em: http://goo.gl/2nF3Sd. Acesso em 22 de março de 2015.

12. MANAUS. Secretaria Municipal de Educação. Proposta Curricular para o 10 Segmento, de Educação de Jovens e Adultos. Manaus 2010.

13. . Resolução CME № 04, de 22/04/2010. Aprova a Proposta Pedagógica da Educação de Jovens e Adultos - 10 Segmento, para as Escolas da Rede Municipal de Ensino.

14. Resolução CME № 07, de 15/09/2011. Normas para Operacionalização da Educação de Jovens e Adultos na Rede Municipal de Ensino de Manaus.

15. PRODANOV, Cleber Cristiano e FREITAS. Ernani Cesar de Freitas. Metodologia do trabalho científico: métodos e técnicas da pesquisa e do trabalho acadêmico. 2a. ed. - Novo Hamburgo: Feevale, 2013.

16. TRIVIÑOS, Augusto Silva. Introdução a Pesquisa em Ciências Sociais. 18a Ed. São Paulo: ATLAS, 2008. 